\title{
The 'CORSAGE' programme: continuous orbital remote sensing of archipelagic geochemical effects
}

\author{
J. G. ACKER ${ }^{1}$, C. W. BROWN ${ }^{2 *}$ and A. C. HINE \\ ${ }^{1}$ Laboratory for Hydrospheric Processes, Code 970, NASA Goddard Space \\ Flight Center, Hughes STX Corporation, Greenbelt, MD 20771, U.S.A. \\ ${ }^{2}$ National Research Council, Laboratory for Hydrospheric Processes, NASA \\ Goddard Space Flight Center, Greenbelt, MD 20771, U.S.A. \\ ${ }^{3}$ Department of Marine Science, University of South Florida, St. Petersburg, \\ FL 33701, U.S.A.
}

(Received 21 September 1995; in final form 24 April 1996)

\begin{abstract}
Current and pending oceanographic remote sensing technology allows the conceptualization of a programme designed to investigate ocean-island interactions that could induce short-term nearshore fluxes of particulate organic carbon and biogenic calcium carbonate from pelagic island archipelagoes. These events will influence the geochemistry of adjacent waters, particularly the marine carbon system. Justification and design are provided for a study that would combine oceanographic satellite remote sensing (visible and infrared radiometry, altimetry and scatterometry) with shore-based facilities. A programme incorporating the methodology outlined here would seek to identify the mechanisms that cause such events, assess their geochemical significance, and provide both analytical and predictive capabilities for observations on greater temporal and spatial scales.
\end{abstract}

\section{Introduction}

Coral reefs are one of the most productive carbonate environments in the ocean. and other neritic environments also possess high carbonate production rates. According to Milliman (1993), coral reefs cover only 0.02 per cent of the total area of the deep (oligotrophic) ocean, yet have a rate of carbonate production approximately 200 times greater than the oligotrophic ocean. Therefore, neritic carbonate production is an important facet of the oceanic carbon cycle.

At a National Science Foundation workshop concerning carbonates in the oceanic system, held near Williamsburg, Virginia in October 1994 (Milliman and Droxler 1995), the amount of production and transport of carbonate materials from southwestern Pacific Ocean reefs and shallow margins (Indonesian and Polynesian) was considered a major unknown in models of the total oceanic carbon budget. Quantification of this component is important, primarily because the dissolution of carbonates in the ocean is a known sink for anthropogenic carbon dioxide $\left(\mathrm{CO}_{2}\right)$ (Sabine and Mackenzie 1991). The response of the saturation state of the Pacific Ocean with respect to calcium carbonate $\left(\mathrm{CaCO}_{3}\right)$ may be an indicator of the rate of transport of anthropogenic $\mathrm{CO}_{2}$ into the water column (Feely et al. 1984).

Several researchers (Droxler et al. 1988, Agegian et al. 1988. Sabine and

*Now at: NOAA/NESDIS, NSC Rm. 105, Washington, DC 20233, U.S.A. 
Mackenzie 1991, 1995) have shown that carbonate production can induce a significant chemical influence on the adjacent water column of the ocean due to the export of neritic carbonates. This effect is most pronounced in regions such as Hawaii and Bermuda, where the productive reefs are surrounded by low-productivity oligotrophic waters. Agegian et al. (1988) calculated that the total production from the shallow reefs and submerged banks of the Hawaiian archipelago is equal to an area of open ocean at least ten times larger. Figure 1 schematically illustrates this relationship. The smaller square shows the approximate total area of the reefs and banks of the Hawaiian archipelago, and the large square indicates the open ocean area that would be required for the same amount of carbonate production in oligotrophic waters. If Milliman's (1993) estimate is used, the area of this larger square would be increased by a factor of 20 - a square with sides $1900 \mathrm{~km}$ in length - to illustrate the difference between estimated global coral reef carbonate production and open ocean carbonate production.

Pelagic archipelagoes are subject to a range of physical oceanographic phenomena, including strong and severe storms, sustained winds, and variable current velocities. In the Atlantic Ocean, the Bermuda platform is also subject to the influence of strong currents due to the occasional incursion of Gulf Stream rings $(\mathrm{H}$. Roberts, personal communication) which alter the normal current regime. Both Hawaii and

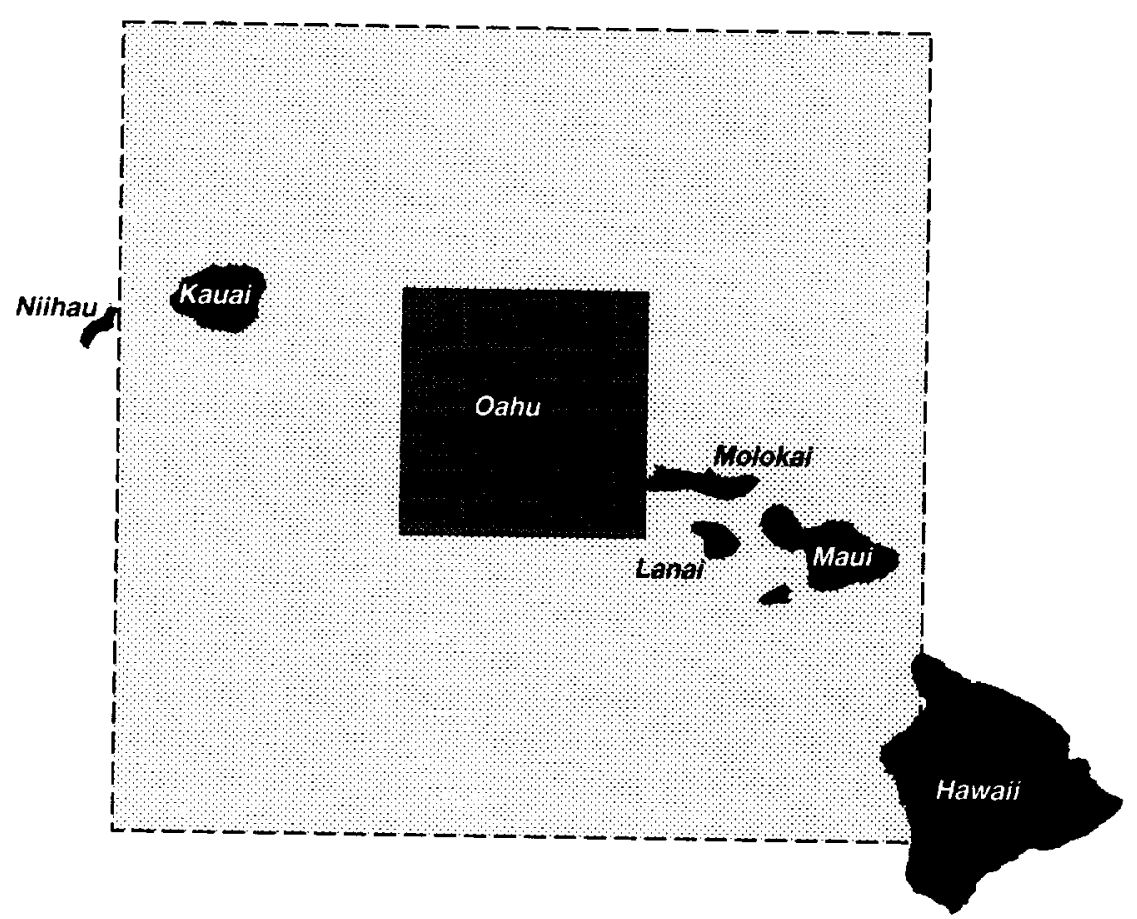

Figure 1. Schematic illustration of the difference between reef and shallow platform carbonate productivity compared to open ocean carbon productivity (Agegian et al. 1988) for the Hawaiian archipelago. The small square represents the total area of the reefs, banks and shoals of the archipelago, and the large square represents an area of open ocean required to produce an amount of carbonates equivalent to Hawaiian reef productivity. If the global production estimates of Milliman (1993) are used for this comparison, the larger square would encompass an area of $1900 \mathrm{~km}^{2}$. 
Bermuda occasionally experience tropical hurricanes, and Hawaii is normally influenced by the prevailing trade winds.

The islands, in turn, influence the chemistry of the adjacent water column due to the export of nutrients, organic carbon, and biogenic $\mathrm{CaCO}_{3}$ in the form of calcite, aragonite, or magnesian calcite. One process of note is storm resuspension of shallow sediments, which can increase nutrient concentrations in the overlying water column for a short period (Fanning et al. 1981). This mechanism could potentially induce brief planktonic blooms as these nutrients are transported offshore. Islands can also act as a source of iron that can induce increased primary production in iron-deficient waters (U.S. Joint Global Ocean Flux Study 1992, 1994, K. Johnson, personal communication).

Off-bank transport of neritic magnesian calcite was shown by Sabine and Mackenzie $(1991,1995)$ to induce a local depression of the carbonate saturation horizons in water close to the banks of the Hawaiian archipelago. Berner et al. (1976) observed the increasing effects of dissolution on carbonate sediments with increasing depth on the Bermuda platform, indicating that much of the neritic carbonate exported from the Bermuda reef complex to the pelagic water column is dissolved at depth.

It is therefore clear that the physical oceanographic interactions and geochemical processes occurring in the vicinity of pelagic archipelagoes can produce a significant influence on the chemistry of adjacent oceanic waters. These phenomena are, and their effects are likely to be, highly variable on short time-scales, and thus may be difficult to observe, investigate and quantify using traditional ship-based sampling methods. Satellite remote sensing can potentially provide periodic and synoptic coverage for investigation of short time-scale events such as those discussed above.

\section{Observational data}

In a preliminary study, Brown and Acker (1994) examined high resolution (1 km) Coastal Zone Colour Scanner (CZCS) imagery of the Bermuda archipelago for surface expressions indicating the transport of neritic carbonate off the shallow Bermuda platform (figure 2). Specifically, images of normalized water-leaving radiance $\left(\mathrm{nL}_{\mathrm{w}}\right)$ in the blue $\left[\mathrm{nL}_{\mathrm{w}}(440)\right]$, green $\left[\mathrm{nL}_{\mathrm{w}}(520)\right]$, and yellow $\left[\mathrm{nL}_{\mathrm{w}}(550)\right]$ bands

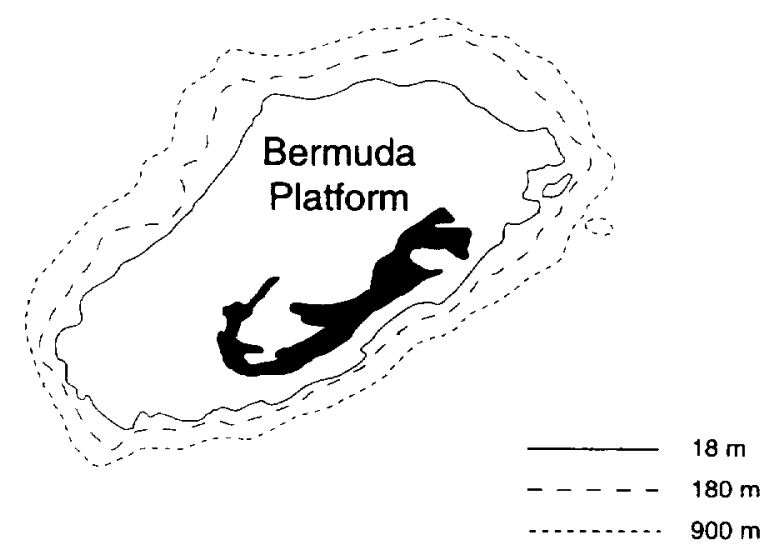

Figure 2. 18,180 and 900 metre isobaths of the Bermuda platform (corresponding to the 10 , 100 , and 500 fathom isobaths). 
were inspected for features exhibiting high water-leaving radiances in some or all of the bands, and extending from the margin of the shallow platform to the open ocean.

High reflectance features of this type, suggesting off-shelf transport of neritic carbonates, were detected in 5 per cent of the 120 images examined. Figures 3-5 show three of these images. Portions of these features, extending at most $10 \mathrm{~km}$
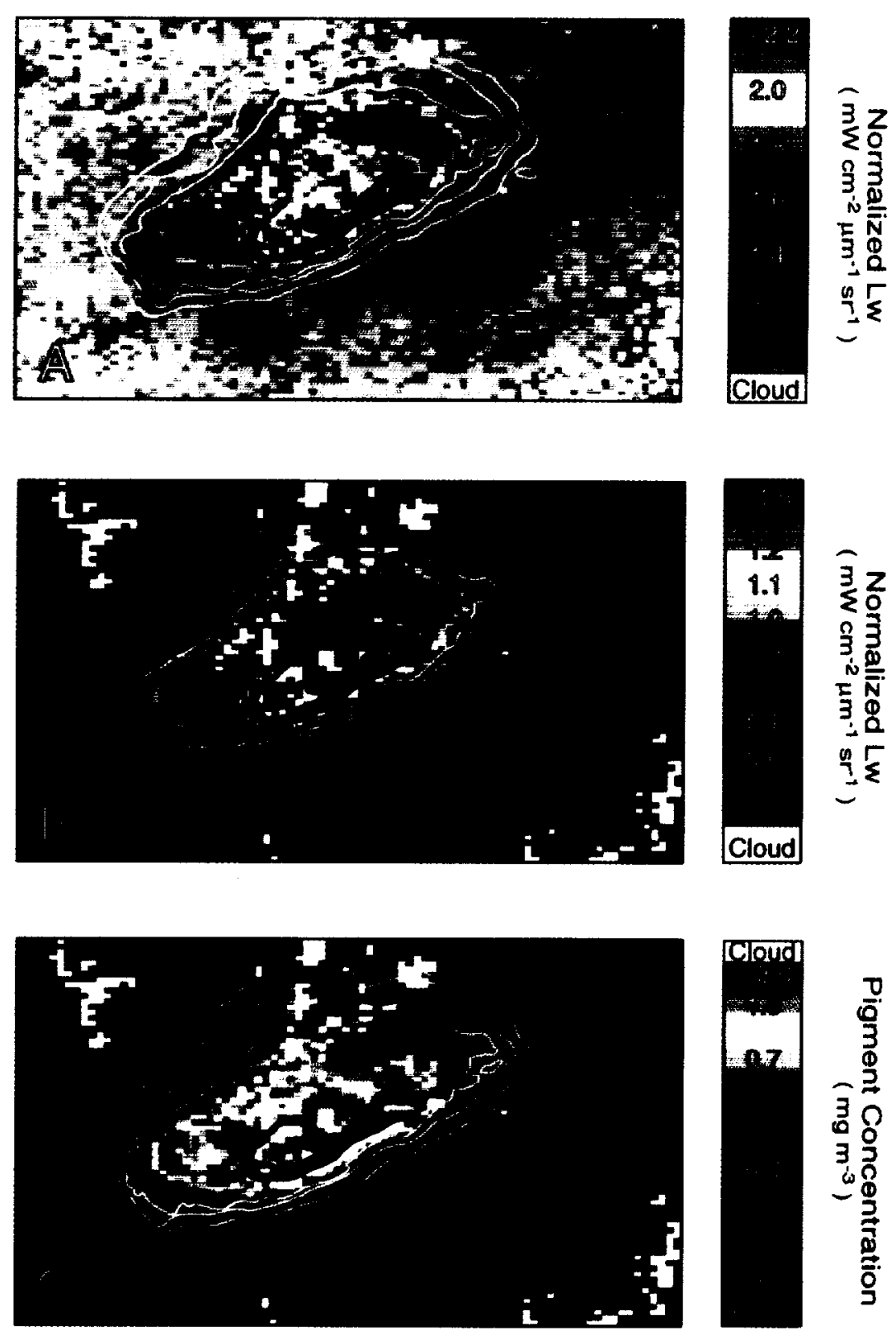

Figure 3. CZCS imagery of normalized water-leaving radiances $\left(\mathrm{nL}_{w}\right)$ at: $(A) i=440 \mathrm{~nm}$; (B) $\lambda=550 \mathrm{~nm}$; and $(C)$ pigment concentration, for the region surrounding Bermuda on 19 August 1982 . The bathymetry is the same as in figure 2. 

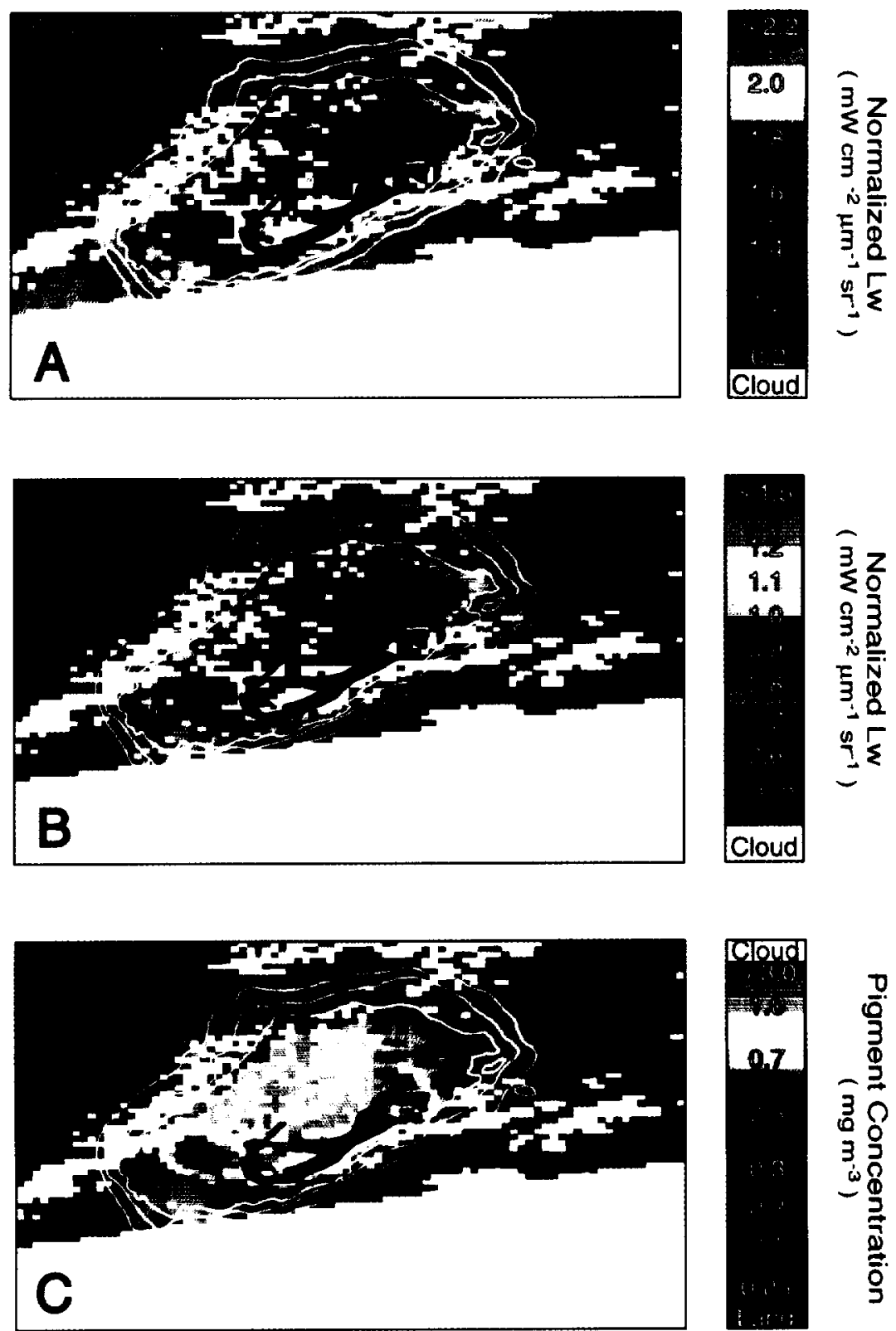

Figure 4. CZCS imagery of normalized water-leaving radiances $\left(\mathrm{nL}_{w}\right)$ at: $(A) i=440 \mathrm{~nm}$; (B) $\lambda=550 \mathrm{~nm}$; and $(C)$ pigment concentration, for the region surrounding Bermuda on 17 September 1982 . The bathymetry is the same as in figure 2.

beyond the 18 metre isobath around Bermuda, revealed water-leaving radiances in the $550 \mathrm{~nm}$ (yellow) band greater than surrounding oceanic waters, and greater than expected for typical phytoplankton blooms, i.e., $0.5 \mathrm{~mW} \mathrm{~cm}{ }^{-2} \mu \mathrm{m}^{-1} \mathrm{sr}^{-1}$ (Gordon and Clark 1981). The features were also characterized by depressed $\mathrm{nL}_{\mathrm{w}}(440)$ relative to surrounding oceanic waters, indicating the presence of chlorophyll $a$, phaeophytin 

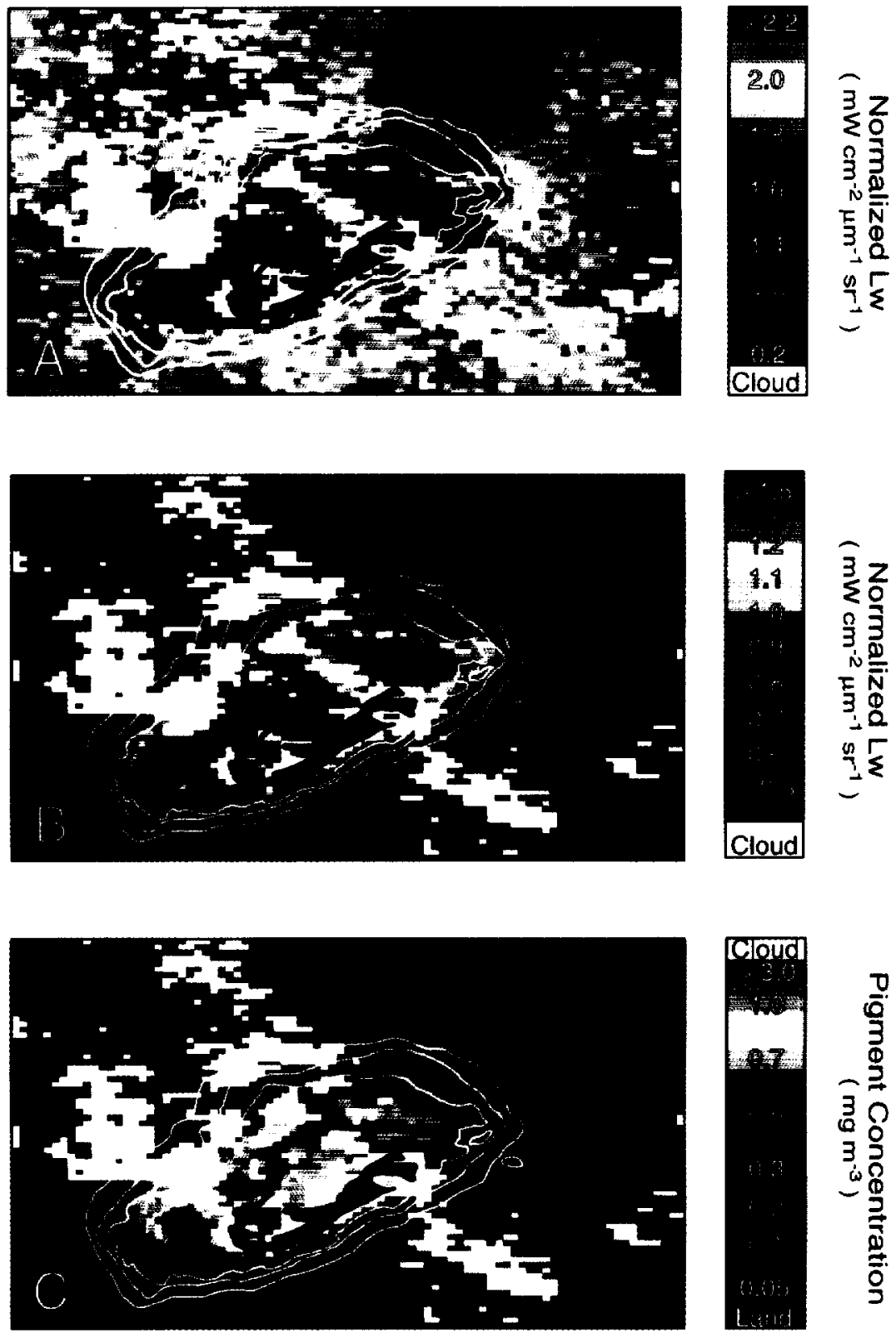

Figure 5. CZCS imagery of normalized water-leaving radiances $\left(\mathrm{nL}_{w}\right)$ at: $(A) \lambda=440 \mathrm{~nm}$ (B) $\lambda=550 \mathrm{~nm}$; and $(C)$ pigment concentration, for the region surrounding Bermuda on 13 October 1983 . The bathymetry is the same as in figure 2 .

(a degraded form of chlorophyll), and/or chromophoric dissolved organic carbon. (The high values of pigment concentration and water-leaving radiances inside the reef zone, which are coloured yellow to red in figures $3-5$, are artifacts caused by bottom reflectance.)

It is noteworthy that each of these features has a slightly different optical signa- 
ture. In figure 4 , the congruency of the pigment (figure $4(C)$ ) and $550 \mathrm{~nm}$ radiance (figure $4(B)$ ) images indicates that the features may be composed primarily of suspended reef carbonates. Both figures 4 and 5 exhibit a similar expression, and they are associated with approximately the same location on the Bermuda reef complex. However, in figure 3 , the marked difference between the pigment radiance (figure $3(C)$ ) and the $\mathrm{nL}_{\mathrm{w}}(550)$ radiance (figure $3(B)$ ) images indicates that these features are likely phytoplankton blooms. As the image appears to show a connection to the reef complex, it is hypothesized that a recent meterological event, preceding image acquisition (i.e., rain and higher winds), caused locally increased nutrient concentrations, stimulating a nearshore bloom.

Features similar to the ones illustrated in figures $3-5$ probably occur more often than is indicated by the number of images found by this preliminary survey. The CZCS on the Nimbus-7 platform was not operated continuously, and hence observations of Bermuda were intermittent. Furthermore, observations of this region are hampered by considerable cloud cover, especially in the winter and spring seasons. The most likely season for major off-bank transport events would be the late summer, due to the possible influence of a hurricane or tropical storm. However, the passage of weather systems causing transport events of lesser magnitude would be expected in the winter. Due to possible water column instability, transient blooms might be expected to occur more often in the spring and autumn.

Another factor that must be considered is the brief temporal persistence of either phytoplankton blooms or sediment transport events. As an example, blooms of the coccolithophore Emiliania huxleyi are likely to exhibit similar optical characteristics to what would be expected for fine neritic carbonate particles. E. huxleyi blooms exhibit high reflectance, and are noteworthy for their transience (Brown and Yoder 1994). In the case of suspended sediments, the rapid sinking rate of carbonate particles larger than coccoliths would markedly decrease their residence time in nearsurface waters. Given these considerations, it is apparent that either localized blooms or active offshore transport of coarse sediments are usually brief in duration, and thus CZCS observation of these features near Bermuda was fortuitous. A focused programme would be expected to obtain many more event observations than have been found in the CZCS archive.

This preliminary survey of available ocean colour images of Bermuda thus indicates the intermittent appearance of nearshore high reflectance features. The features observed are provisionally identified as mixed assemblages of phytoplankton chlorophyll and suspended neritic carbonate particles. However, the oceanographic processes that induce the occurrence of such features cannot be ascertained from a single data source. The determination of the causes and frequency of occurrence of such features requires a dedicated multi-sensor observational programme.

\section{Plankton blooms and off-bank transport}

The geochemical influence of pelagic archipelagoes on adjacent ocean waters will take one of two forms. The first form is that of a plankton bloom, i.e., a rapid increase in the biomass of living phytoplankton in surface waters. As the waters surrounding Bermuda and Hawaii are oligotrophic, an increase in nutrient concentration could generate the formation of a bloom. As noted previously, nutrient concentrations may be elevated in waters adjacent to islands by several different mechanisms. One nutrient source would be increased run-off from the land surface, and delivery 
to the ocean via rivers and streams. This mechanism is most important for large islands, and clearly not a factor for small islands, shallow carbonate banks, or reefs.

Another mechanism is sediment resuspension, which can allow nutrients that were sequestered into the sediments to re-enter overlying waters. Storms, frontal passages, and increased current velocities could all cause some sediment resuspension and delivery of nutrients to the water column. Note that if a bloom was induced by any of these processes, the optical signature of the oceanic feature would be a combination of effects from chlorophyll absorption and sediment reflectance.

An additional mechanism capable of enhancing phytoplankton productivity is the delivery of iron to the oligotrophic water column in regions of low iron concentration (Martin and Gordon 1988, Young et al. 1991). Iron derived from the deposition of volcanic ash in shallow sediments has been suggested as a vital nutrient contributing to the higher-productivity waters observed near the Galapagos archipelago (Feldman et al. 1984, Feldman 1986). Strong winds, which could suspend dust or soil in the atmosphere, could also lead to increased iron availability, and augment ocean biological productivity. The size and geological identity of an island will determine the importance of archipelagically derived iron to the productivity of the adjacent ocean.

The interaction of currents with an island platform can also cause localized upwelling of waters with increased nutrient concentrations (Feldman et al. 1984, Feldman 1986, Hallock and Elrod 1988, Hallock et al., 1988). Feldman (1986) noted that the interactions of island structures with wind-driven ocean currents will cause Ekman upwelling of deep nutrient-rich waters, fostering a productivity plume observable in ocean colour remote sensing. Alteration of the current regime around an island, due to an increase in wind-driven current velocity or the passage of a ring, may also induce a greater amount of upwelling near the island.

The mechanisms by which biogenic carbonate, produced by corals and calcareous algae, are exported from the reef flat to the open ocean water column are of considerable geologic interest (Mackenzie et al. 1965, Land 1979, Hine et al. 1981, Heath and Mullins 1984, Agegian et al. 1988, Glaser and Droxler 1991). According to this research, reef carbonates may be horizontally advected $100 \mathrm{~km}$ and deposited up to $200 \mathrm{~km}$ from a source region. Mackenzie et al. (1965) used detritus from Homotrema rubrum, which grows on the outer reef shoal of Bermuda, as a diagnostic indicator of sediment transported from the platform. Many instances of off-bank surface flows are wind-driven, but this process is dependent on whether or not the reef is on the predominately windward or leeward margin of the island. Windinduced swells and surf can also impart a great deal of energy to the reef, causing considerable sediment resuspension. The impingement of strong currents could also cause sediment resuspension and off-bank transport of neritic carbonates from an archipelago.

In the specific case of Bermuda, the movement of a Gulf Stream ring over the platform would significantly increase current speeds, leading to current sweeping of sediments and associated nutrients off the reef and shallow regions of the platform. Such an event, accompanied by resuspension of sediments, could result in a sudden and significant input of carbonate sediments into the adjacent deep ocean (H. Roberts, personal communication).

Bermuda would also be subject to a meteorologic cause for off-bank transport of neritic carbonates, which has been described by Wilson and Roberts (1992) for the Bahamas. In this mechanism, passage of a cold front induces wave suspension 
of sediments, and also induces a temperature differential with the oceanic water column due to surface cooling. This cooling causes a density difference between the water on the shallow carbonate platform and open ocean sea water. Subsequently, the denser water mass, carrying suspended sediments, will flow downslope to the equilibrium pycnocline, where further transport will be due to horizontal advection. This mechanism would be very important for Bermuda, as the island is subject to the influence of several cold front passages during the winter season. (U.S. Joint Global Ocean Flux Study 1990). Note that the primary direction of sediment transport by this mechanism would be vertical. Thus, any surface turbidity due to sediment suspension that would be generated by such an event (and observable in remotely sensed imagery) would likely provide only a minimal estimate of the event magnitude.

The mechanisms of off-bank transport in Hawaii do not appear as complex as the variety of factors that could influence Bermuda. Wind-driven transport is likely to be the primary mode of transport for the reefs of the Hawaiian archipelago. Offbank transport from these banks has been observed from aircraft (Mackenzie, personal communication). Hawaii can be subject to some variation in wind velocities due to climatologic factors such as El Niño, and the occasional passage of a hurricane. Wyrtki et al. (1969) also suggest the tidal cycle as an important factor in the current regime for some of Hawaii's carbonate banks. Moberly et al. (1975) notes that there is little sediment accumulation on the top of Penguin Bank, south-east of Molokai, indicating the influence of a strong transport mechanism.

In terms of nutrients, the volcanic nature of the Hawaiian islands, similar to the Galapagos archipelago, would indicate that iron input would be more important there than for Bermuda. However, Young et al. (1991) observed an increase in primary productivity attributed to iron from Gobi Desert material transported to the water column north of Hawaii. Bermuda could also receive such an input from the Sahara Desert.

Once sediments have been transported from the shallow reef and bank environment to the pelagic ocean, the chemistry of the carbon system in the adjacent water column will determine the eventual fate of neritic carbonates. The water column off Bermuda does not become undersaturated with respect to any carbonate phases until approximately 2500 metres depth. Berner et al. (1976) demonstrated the effects of increasing dissolution on carbonates below this depth on the Bermuda platform. Thus, carbonates transported below this depth in the Atlantic will be subject to dissolution.

In contrast, the aragonite saturation horizon near Hawaii lies at approximately $500 \mathrm{~m}$ depth, and is slightly shallower for magnesian calcite, which is more soluble than aragonite. Sabine (1992) and Sabine and Mackenzie (1991, 1995) demonstrated that the dissolution of neritic carbonate material at relatively shallow depths depresses the aragonite saturation horizon in the vicinity of Penguin Bank (southwest of Molokai) and the Hawaiian archipelago.

It is therefore clear that Hawaii and Bermuda are archetypal pelagic island archipelagoes with fringing reefs or shallow carbonate banks, similar in their oceanographic setting as isolated island systems, yet dissimilar in several important aspects. The study of these two locations should allow considerable insight into the mechanisms by which such islands can influence the geochemistry of the adjacent ocean. 


\section{Study concept}

For the purpose of studying the generation of phytoplankton blooms and offbank neritic carbonate transport events near pelagic islands, the authors have conceptualized a programme named CORSAGE (Continuous Orbital Remote Sensing of Archipelagic Geochemical Effects). While this acronym emphasizes the use of remote sensing, it should be immediately noted that a programme of in situ observations and sampling will be an integral part of this study.

In broad outline, CORSAGE will seek to develop a diagnostic capability for short-lived high reflectance features near islands that are visible in ocean colour imagery, similar to the features shown in figures 3-5 near Bermuda. By utilizing data from several remote sensing techniques, the programme would develop a set of observational indicators tied to the occurrence of transient high reflectance features. CORSAGE would also determine the conditions that are most likely to induce offbank transport events and local phytoplankton blooms, and ascertain the detectability of these events in ocean colour imagery.

Initially, monitoring of the archipelago to allow detection of short-lived features would be emphasized, with subsequent hindcasting using remotely sensed data to elucidate probable mechanisms for feature generation. Subsequently, having gained a basic understanding of the mechanisms that generate such features, the study would move into a fast-response observational phase, in which predictions of feature occurrence would coincide with active sampling efforts, for the determination of the actual nature of an observed event (bloom, sediment, or mixture), as well as spatial (horizontal and vertical) extent and temporal duration of the event. This study phase would allow a complete description of the observed phenomena, and estimation of its geochemical impact. The ADIOS (Asian Dust Inputs to the Ocean System) programme (Betzer et al. 1988, Young et al. 1991) demonstrated the feasibility of this type of observational programme.

In the final phase of the study, a combination of predictive capability and signal recognition would allow the use of remote sensing data from other regions to identify similar phenomena. Basin-scale and global integration of the data would allow assessment of the importance of these processes in ocean geochemistry, and could also guide future research efforts in remote areas, such as the Indonesian reef complex.

\section{Remote-sensing capability}

One reason that CORSAGE is being proposed as a feasible study at this time is the current and pending suite of available oceanographic remote-sensing instruments, unprecedented in the history of ocean science. The initial phase of CORSAGE would require only a modest investment in computing and data storage, to assimilate and correlate observational data from the study regions. As the regions of interest are relatively small, relatively modest data volumes (compared to basin-scale or global research) would allow comprehensive monitoring of these regions. The requirements for personnel and equipment to perform data acquisition and assimilation would also be controlled by the data analysis requirements.

Several techniques have been utilized to study the transport of sediments and particles with remote sensing and in situ sampling. As examples of this type of study, Stumpf (1992) described the use of the Advanced Very High Resolution Radiometer (AVHRR) for imagery of turbid waters. Otero et al. (1992) combined in situ sampling with the Calibrated Airborne Multispectral Scanner (CAMS) to investigate offshore plumes from several Puerto Rican rivers. Carder et al. (1992) observed sediment 
transport from Tampa Bay using the Airborne Visible-Infrared Imaging Spectrometer (AVIRIS), and noted that coincident in situ sampling would aid interpretation of the remote sensing data.

Studies similar to the CORSAGE concept, where satellite observations of ocean colour or turbidity are combined with in situ sampling, are uncommon. One example is that of Forster et al. (1994), who describe a programme of in situ sampling combined with Landsat Thematic Mapper (TM) imagery. This research group investigated a region near a sewage outfall in coastal waters offshore of Sydney, Australia, by mapping particle-size distributions and comparing their particle-size distribution model to a Landsat image of the area.

The following paragraphs briefly describe the various types of remote sensing data, existing and pending orbital sensors, and the use of this data in the CORSAGE programme.

\subsection{Visible radiometry}

Ocean colour. Ocean colour data would be utilized primarily to determine the extent and variability of near-surface indications of off-bank transport of neritic carbonates, and the occurrence of phytoplankton blooms in the vicinity of the islands. The features shown in figures 3-5 were found in CZCS imagery, so ocean colour data is expected to be a useful data source. However, ocean colour is constrained somewhat by the shallow depths at which optical phenomenon can be detected, by sensor coverage, and by cloud interference that blocks the view of the ocean surface.

As of mid-1995, there are currently no dedicated orbital ocean colour sensors. The NASA Sea-viewing Wide Field-of-view Sensor (SeaWiFS) anticipates a 1996 launch, as does Japan's National Space Development Agency (NASDA) Ocean Colour Temperature Sensor (OCTS). Once both sensors are in operation, at least one view of regions of interest could be obtained daily. SeaWiFS Local Area Coverage (LAC) 1-km resolution data should be obtained by the Bermuda Biological Station for Research (BBSR) and the University of Hawaii.

Furthermore, the presence of the SeaWiFS Marine Optical Buoy (MOBY) off Lanai makes Hawaii an important target for SeaWiFS calibration and validation purposes, and therefore much of the SeaWiFS onboard LAC storage capability will be for imagery of the Hawaiian archipelago. In the future, both the French Medium Resolution Imaging Spectrometer (MERIS) and the NASA Moderate Resolution Imaging Spectroradiometer (MODIS) will provide ocean colour data in the late 1990 s and into the next century.

\subsection{Visible/IR}

Meteorological. Imagery from Geostationary Operational Environmental Satellites (GOES) is very useful for the predictive element of CORSAGE. Meteorological observations provide indications of weather systems (cold fronts and storms) that will influence the islands and adjacent waters.

As off-bank transport has been shown to depend on a variety of meteorologically induced mechanisms, monitoring the meteorological conditions affecting Hawaii and Bermuda will be vital in the development of predictive skill. As previously noted, the use of this data initially will be in 'hindcast' mode, i.e., once a feature has been seen in remotely sensed imagery, the meteorological images can be reviewed to determine any factors that may have generated the feature. Subsequently, the data could be used to predict the occurrence frequency of transport events and blooms. 
5.3. IR/Visible

Sea surface temperature ( $S S T$ ). SST data, primarily available now from the AVHRR on National Oceanic Atmospheric Administration (NOAA) polar-orbiting environmental satellites, will aid CORSAGE in the observation of ocean currents that influence the study region. These observations are particularly important with regard to Bermuda and the Gulf Stream system, particularly the occasional interaction of the island and a Gulf Stream ring. It is also noteworthy that changes in a ring interacting with an island could be observable in both ocean colour and SST, giving a comprehensive picture of the biological and physical effects of such a passage. While the oceanic currents influencing Hawaii are not as variable as those near Bermuda, AVHRR could provide some data on the local current structure and mesoscale eddies in the region.

The magnitude of surface water chilling events (Wilson and Roberts 1992) can also be estimated using AVHRR. Recently, the phenomenon described by Wilson and Roberts (1992) for the Bahamas archipelago was observed in near-real-time, using AVHRR imagery obtained 5-11 February 1996, following the passage of a severe cold front. Both the rapid cooling of the shallow platform waters and the movement of chilled water off the banks was evident. As this phenomenon is still poorly characterized with regard to sediment dynamics (Wilber et al. 1993, Wilson and Roberts 1993), yet occurs frequently and is predictable in advance, the Bahamas may be suitable for a CORSAGE pilot study.

In addition to the AVHRR, several other SST sensors are either in orbit or planned for the near future, making this a vital data type. Correlation of ocean colour data from SeaWiFS and ERS radiometry or AVHRR could be another activity of CORSAGE.

The visible wavelength AVHRR channel has been used to detect turbid water conditions (notably for sediment-laden river outflows). If the features under observation are sufficiently turbid, this channel might also be used in concert with ocean colour observations to observe the evolution of the features over time, and also help to distinguish suspended sediments from phytoplankton chlorophyll.

\subsection{Active microwave}

Sea surface height. The use of altimetry to track ocean eddies has been demonstrated in previous studies (Gordon and Haxby 1990, Johnson et al. 1992). An advantage of altimetry is that it can operate in the presence of cloud cover, allowing tracking of ocean surface features while visible and IR sensors are occluded. For Bermuda, altimetry enables the tracking of Gulf Stream rings that might interact with the platform. For Hawaii, altimetry can provide information on ring systems that could influence the islands, though they are likely to be weaker than Gulf Stream rings. Altimetry can also be used to indicate the state of the Pacific Ocean El Niño/Southern Oscillation (ENSO) phenomenon, which can affect the strength of trade winds in the Hawaiian islands.

Altimetry data is currently available from TOPEX/Poseidon and both ERS-1 and ERS-2. The U.S. Navy Geosat Follow-On (GFO) mission is pending, and additional missions are advocated for the next century.

\subsection{Active microwave}

Vector surface winds. Scatterometry of capillary ocean waves provides additional information on wind speed and direction over the oceans. While CORSAGE will 
benefit from land-based meteorological observations, scatterometry data will augment data from GOES satellites for storms and frontal patterns over the ocean. In the case of Hawaii, the data will aid observation of meteorological conditions over the extended archipelago, i.e., occurring at a considerable distance from the five main islands. Some of the most productive reefs between Hawaii and Midway Island, such as French Frigate Shoals, Gardner Pinnacles, and Necker Island, are highly visible in CZCS imagery due to their shallow depth. Scatterometry allows a characterization of the wind field in a large area of the ocean surrounding the islands.

Scatterometry data is currently available from ERS-1. In 1996, scatterometry data will become available from NSCAT on the NASDA Advanced Earth Observing Satellite (ADEOS), which will also carry OCTS. This deployment offers the possibility of correlated vector wind and ocean colour observations, which could be of great use to the CORSAGE programme.

\subsection{At-sea research}

It is not coincidental that the proposed study sites are also the location of the observational oceanographic time-series stations in the international Joint Global Ocean Flux Study (JGOFS). Proximity to an oceanographic laboratory such as the BBSR or the University of Hawaii, with the associated expertise in at-sea sampling, provides the necessary ship availability and scientific expertise that would be necessary to investigate the identity of a transient feature. It would likely be necessary to have real-time data access in order to determine the feature locations and to obtain samples of the water column within and in the vicinity of the feature. These samples would then be analysed in shore laboratories by a variety of procedures. Optimal sampling strategies would be required in order to characterize a feature for the entire duration of the event. In particular, particle size analysis combined with determination of elemental composition, using a scanning electron microscope with energydispersive X-ray analysis (SEM/EDXA) would allow accurate discrimination of particle identities in collected samples.

As expertise in predicting and locating surface optical features is developed, more extensive sampling methodology could be applied, including methods which would characterize the three-dimensional aspect of a feature. Sediment trap deployment, acoustic doppler current profiles (ADCP) (Kraus et al. 1992), and other techniques would allow a comprehensive characterization of the feature.

\section{Study design}

The following is a short outline of the phases of the CORSAGE programme.

Phase 1. The first phase would require the establishment of a centralized data archive centre, with sufficient computing power and data storage capability to allow image acquisition and analysis from several different sources. Links to the data sources which hold the desired observational data would be set up. To develop expertise in the use of the data, a review of the existing archive of remotely sensed data for these regions would take place, possibly indicating past events of interest.

Estimated duration of this phase: 6 months.

Phase 2: Once the data centre is established, CORSAGE would commence an intensive monitoring effort. Observations from all available sensors would be used to construct a daily observational record of the Hawaiian and Bermudan archipelagoes. As the records are developed, examination of the observational data would 
lead to a climatological profile of significant forcing mechanisms. As expertise is developed, tentative forecasting and success evaluation would then take place.

Estimated duration of this phase: 1.5 to 2 years.

Phase 3: With a developed forecast capability, CORSAGE would then move into the identification and characterization phase. Research cruises would be scheduled for those times where a strong likelihood of feature occurrence is predicted. Aircraft deployment would be coordinated with these cruises. It would be desirable to have a 'standby alert' sampling capability for event predictions with limited pre-event indications. (This capability might be more feasible for Bermuda than for Hawaii, as the available imagery indicates that the features are located very close to the reef boundary.) In the case of Hawaii, a standby aircraft could allow sampling of events over the archipelago. Given the extent of the Hawaiian archipelago, ship deployment would require more lead time than for Bermuda.

In conjunction with these efforts, and hopefully during the same research cruises, a geologic characterization of the sedimentary environment would be carried out. The Late Quaternary sedimentary apron around the islands would be imaged via high resolution seismic reflection profiling. The sediments would be cored and the cores examined to determine the spatial and temporal extent of blooms and off-bank transport events in the recent geologic past.

It may also be possible, given current efforts in the development of Autonomous Underwater Vehicles (AUVs), that an AUV could be deployed to sample these features (A. Bennett, personal communication). CORSAGE could provide a stringent testing programme for oceanographic AUV technology.

Estimated duration of this phase: 1 year.

Phase 4: The final phase of CORSAGE would involve the analysis of all relevant data, and a synthesis of results. These results would then be utilized by oceanographic research in the next century to maintain a record of the occurrence of archipelagic ocean optical features and their identity. The database of multi-sensor observations of the Hawaiian and Bermudan archipelagoes will also be a climatologic record of the primary factors inducing sediment transport events and transient phytoplankton blooms. Such a database would be very useful to investigations in the somewhat inaccessible region of the Indonesian reef complex, allowing identification of areas of significant interest.

One of the main goals of CORSAGE would be an accurate quantification of the impact of the Hawaiian and Bermudan archipelagoes on the geochemistry of the adjacent ocean water column. Another goal would be the application of this data to refined models of the ocean carbon system.

Estimated duration of this phase: $6-8$ months.

\section{Summary}

The CORSAGE programme would seek to utilize the increasing suite of oceanographic satellite instrumentation to characterize a significant element of the oceanic carbon system, an element that is at present only partially understood. CORSAGE would combine several data types in the study of a particular phenomenon, demonstrating the application of this technology in a synergistic manner that has not been previously possible. CORSAGE could also serve as a pilot project for similar oceanographic studies. Given the increasing costs of at-sea research, and the rapidly increasing availability of ocean remote sensing data, CORSAGE would be an innovative programme for twenty-first century oceanography. 


\section{Acknowledgment}

The work was performed while C.W.B. held a National Research Council Associateship at Goddard Space Flight Center.

\section{References}

Agegian, C. R., Mackenzie, F. T., Tribble, J. S. and Sabine, C. L., 1988, Carbonate production and flux from a mid-depth ecosystem, Penguin Bank, Hawaii. In Biogeochemical Cycling and Fluxes Between the Deep Euphotic Zone and Other Oceanic Realms, NURP Research Report 88-1, edited by C.R. Agegian (Rockville, MD: NOAA), pp. 5-32.

Berner, R. A., Berner, E. K. and Keir, R. S., 1976, Aragonite dissolution on the Bermuda Pedestal: Its depth and geochemical significance. Earth and Planetary Science Letters, 30, 940-942.

Betzer, P. R., Carder, K. L., Duce, R. A., Merrill, J. T., Tindale, N. W., Uematsu, M., Costello, D. K., Young, R. W., Feely, R. A., Breland, J. A., Bernstein, R. E. and GreCo, A. M., 1988, Long-range transport of giant mineral aerosol particles. Nature, 336, $568-571$.

Brown, C. W. and ACKER, J. G., 1994, CZCS imagery of transient ocean color features near Bermuda: Phytoplankton blooms, offshore transport of shallow reef carbonates, or both? EOS, Transactions of the AGU, 75, Supplement, 195.

Brown, C. W. and Yoder, J. A., 1994, Distribution pattern of coccolithophorid blooms in the western North Atlantic. Continental Shelf Reseurch, 14, 175-198.

Carder, K. L., Steward, R. G., Chen, R. F., Hawes, S. and Z. Lee, 1992, AVIRIS calibration and application in coastal oceanic environments: Tracers of soluble and particulate constituents of the Tampa Bay coastal plume. Proceedings of the 1st Thematic Conference on Remote Sensing for Marine and Coastal Environments, New Orleans, Louisiana, 15-17 June 1992, SPIE 1930 (Ann Arbor, MI: Environmental Research Institute of Michigan), pp. 487-493.

Droxler, A. W., Morse, J. W. and Kornicker, W. A., 1988, Controls on carbonate mineral accumulation in Bahamian basins and adjacent Atlantic Ocean sediments. Journal of Sedimentary Petrology, 58, 120-130.

Fanning, K. A., Carder, K. L. and Betzer, P. R., 1981, Sediment resuspension by coastal waters: a potential mechanism for nutrient re-cycling on the ocean's margins. DeepSea Research, 29, 953-965.

Feely, R. A., Byrne, R. H., Betzer, P. R., Gendron, J. F. and Acker, J. G., 1984, Factors influencing the degree of saturation of the surface and intermediate waters of the North Pacific Ocean with respect to aragonite. Journal of Geophysical Research, 89, $10,631-10,640$.

Feldman, G. C., Clark, D. and Halpern, D., 1984, Satellite color observations of the phytoplankton distribution in the eastern equatorial Pacific during the 1982-1983 El Niño. Science. 226, 1069-1071.

Feldman, G. C., 1986, Patterns of phytoplankton production around the Galapagos Islands. In Tidal Mixing and Plankton Dynamics; Lecture Notes on Coastal and Estuarine Studies, edited by J. Bowman, M. Yentsch, and W. T. Peterson (Berlin: SpringerVerlag), pp. 77-106.

Forster, B., BaIDE, X. and Xingwai, S., 1994, Modelling suspended particle distribution in near coastal waters using satellite remotely-sensed data. International Journal of Remote Sensing, 15, 1207-1219.

Glaser, K. S. and Droxler, A. W., 1991, High production and highstand shedding from deeply submerged carbonate banks, Northern Nicaragua Rise. Journal of Sedimentary Petrology, 61, 128-142.

Gordon, A. L. and Haxby, W. F., 1990, Agulhas eddies invade the South Atlantic: Evidence from Geosat altimeter and shipboard conductivity-temperature-depth survey. Journal of Geophysical Research, 95, 3117-3126.

Gordon, H. R. and ClaRK, D. K., 1981, Clear water radiances for atmospheric correction of coastal zone color scanner imagery. Applied Optics, 20, 4175-4180.

Hallock, P. and Elrod, J. A., 1988, Oceanic chlorophyll around carbonate platforms in the 
western Caribbean: Observations from CZCS data. Proceedings of the 6th International Coral Reef Symposium, Townsville, Australia, 8-12 August 1988 (Townsville: 6th Intl. Coral Reef Symposium Executive Committee), pp. 449-454.

Hallock, P., Hine, A. C., Vargo, G. A., Elrod, J. A. and JaAP, W. C., 1988, Platforms of the Nicaraguan Rise: Examples of the sensitivity of carbonate sedimentation to excess trophic resources. Geology, 16, 1104-1107.

Heath, K. C. and Mullins, H. T., 1984, Open-ocean, off-bank transport of fine-grained carbonate sediment in the northern Bahamas. In Fine-Grained Sediments: Deep Water Processes and Facies, Geological Society of London Special Publication 11, edited by D. A. V. Stow and D. J. W. Piper (London: Blackwell Science Publishers), pp. 199-208.

Hine, A. C., Wilber, R. J., Bane, J. M., Neumann, A. C. and Lorenson, K. R., 1981, Offbank transport of carbonate sands along open leeward bank margins: northern Bahamas. Marine Geology, 42, 327-348.

Johnson, D. R., Thompson, J. D. and Hawkins, J. D., 1992, Circulation in the Gulf of Mexico from Geosat altimetry during 1985-1986. Journal of Geophysical Research, 97(C2), 2201-2214.

Kraus, N. C., Thevenot, M. M. and Lohrmann, A., 1992, PlUMES: An integrated acoustic and in-situ sampling system for synoptic measurement of sediment concentration, current, and position. Proceedings of the 1st Thematic Conference on Remote Sensing for Marine and Coastal Environments, New Orleans, Louisiana, 15-17 June 1992, SPIE 1930 (Ann Arbor, MI: Environmental Research Institute of Michigan), pp. 377-390.

LAND, L. S., 1979, The fate of reef-derived sediment on the North Jamaican island slope. Marine Geology, 29, 55-71.

Mackenzie, F. T., Kulm, L. D., Cooley, R. L., and Barnhart, J. T., 1965, Homotrema rubrum (Lamarck), a sediment transport indicator. Journal of Sedimentary Petrology, $35,265-272$.

Martin, J. H. and Gordon, R. M., 1988, Northeast Pacific iron distributions in relation to phytoplankton productivity. Deep-Sea Research, 35, 177-196.

Milliman, J. D., 1993, Production and accumulation of calcium carbonate in the ocean: budget of a nonsteady state. Global Biogeochemical Cycles, 7, 927-957.

Milliman, J. D. and Droxler, A. W., 1995, Calcium carbonate sedimentation in the global ocean: linkages between the neritic and pelagic environments. Oceanography, 8(3), 92-93.

Moberly, R., Campbell, J. F. and Coulborn, W. T., 1975, Offshore and other sand resources for Oahu, Hawaii. University of Hawaii at Hilo Sea Grant Program, Technical Report 75-03.

Otero, E., Miller, R. L. and Lopez, J. M., 1992, Remote sensing of chlorophyll and sediments in coastal waters of Puerto Rico. Proceedings of the 1st Thematic Conference on Remote Sensing for Marine and Coastal Environments, New Orleans, Louisiana, 15-17 June 1992, SPIE 1930 (Ann Arbor, MI: Environmental Research Institute of Michigan), pp. 353-364.

SABINE, C. L. and MaCkenziE, F. T., 1991, Oceanic sinks for anthropogenic $\mathrm{CO}_{2}$. International Journal of Energy-Environment-Economics, 1, 119-127.

SABINE, C. L., 1992, Geochemistry of particulate and dissolved inorganic carbon in the central Pacific Ocean. PhD thesis, University of Hawaii.

SABINE, C. L. and MACKEnZIE, F. T., 1995, Bank-derived carbonate sediment transport and dissolution in the Hawaiian archipelago. Aquatic Geochemistry, 1, 189-230.

STUMPF, R. P., 1992, Remote sensing of water clarity and suspended sediments in coastal waters. Proceedings of the Ist Thematic Conference on Remote Sensing for Marine and Coastal Environments, New Orleans, Louisiana, 15-17 June 1992, SPIE 1930 (Ann Arbor, MI: Environmental Research Institute of Michigan), pp. 293-306.

U.S. Joint Global Ocean Flux Study Steering Committee (editors), 1990, Long Range Plan. U.S. JGOFS Planning Report Number 11, U.S. JGOFS Planning Office/Woods Hole Oceanographic Institution, Woods Hole, Massachusetts.

U.S. Joint Global OCEan Flux Study Steering Committee (editors), 1992, Design for a Mesoscale Iron Enrichment Experiment. U.S. JGOFS Planning Report Number 15, U.S. JGOFS Planning Office/Woods Hole Oceanographic Institution, Woods Hole, Massachusetts. 
U.S. JoInt Global OCEan Flux Study, 1994, An open-ocean test of the iron hypothesis. U.S. JGOFS News, 5, pp. 1 and 10-11.

Wilber, R. J., Whitehead, J., Halley, R. B. and Milliman, J. D., 1993, COMMENT on 'Carbonate periplatform sedimentation by density flows: A mechanism for rapid offbank and vertical transport of shallow-water fines.' Geology, 21, 667-668.

WILSON, P. A. and RoBerTS, H. H., 1992, Carbonate-periplatform sedimentation by density flows: A mechanism for rapid off-bank and vertical transport of shallow-water fines. Geology, 20, 713-716.

Wilson, P. A. and Roberts, H. H., 1993, Reply to Wilber et al. (1993). Geology, 21, 668-669.

Wyrtki, K., Burks, J. B., Latham, R. C. and Patzert, W., (editors), 1969, Oceanographic observations during 1965-1967 in the Hawaiian Archipelago. Report HIG-67-15, Hawaii Institute of Geophysics, University of Hawaii.

Young, R. W., Carder, K. L., Betzer, P. R., Costello, D. K., Duce, R. A., Ditullio, G. R., Tindale, N. W., Laws, E. A., Uematsu, M., Merrill, J. T. and Feely, R. A., 1991, Atmospheric iron input and primary productivity: Phytoplankton responses in the North Pacific. Global Biogeochemical Cycles, 5, 119-134. 
